\title{
Quasi-static and high-rate mechanical behavior of aluminum-based MMC reinforced with boron carbide of various length scales
}

\author{
Nathan Behm ${ }^{\mathrm{a}, \mathrm{b}^{*}}$, Hanry Yang ${ }^{\mathrm{c}, \mathrm{e}}$, Jianghua Shen ${ }^{\mathrm{b}}$, Kaka Ma ${ }^{\mathrm{c}, \mathrm{d}}$, Laszlo J. Kecskes ${ }^{\mathrm{f}}$, Enrique \\ J. Lavernia ${ }^{c, d}$, Julie M. Schoenung ${ }^{c, d^{*}}$, Qiuming Wei ${ }^{b}$ \\ ${ }^{a}$ Nanoscale PhD Program, University of North Carolina at Charlotte, 9201 University \\ City Blvd, Charlotte, NC 28223-0001, USA \\ ${ }^{b}$ Department of Mechanical Engineering and Engineering Science, University of North \\ Carolina at Charlotte, 9201 University City Blvd, Charlotte, NC 28223-0001, USA \\ ${ }^{\mathrm{c}}$ Department of Chemical Engineering and Materials Science, University of California- \\ Davis, One Shields Ave., Davis, CA 95616, USA \\ ${ }^{\mathrm{d}}$ Department of Chemical Engineering and Materials Science, University of California- \\ Irvine, Irvine, CA 92697, USA \\ ${ }^{\mathrm{e}}$ School of Mechanical and Materials Engineering, Washington State University, \\ Pullman, WA 99164, USA \\ ${ }^{\mathrm{f}}$ WMRD US Army Research Laboratory, Aberdeen Proving Ground, Aberdeen, MD
} 21005, USA

A manuscript submitted to Materials Science and Engineering: A for publication

*Corresponding Authors: Tel: +1 704687 8219; fax: +1 7046878345 .

Electronic mails: julie.schoenung@uci.edu; nbehm@uncc.edu. 


\begin{abstract}
We report on an investigation of the quasi-static and dynamic mechanical behavior of an ultrafine-grained (UFG) aluminum composite reinforced with nanoscale boron carbide under uniaxial compression. Aluminum composites reinforced with either nanometric or half-micron sized $\mathrm{B}_{4} \mathrm{C}$ exhibit high strength $\sim 900 \mathrm{MPa}$ and considerable strain-to-failure under compression $\left(>15\right.$ pct.) at quasi-static $\left(10^{-3} \mathrm{~s}^{-1}\right)$ and dynamic $\left(10^{3} \mathrm{~s}^{-}\right.$ $\left.{ }^{1}\right)$ strain rates. Microstructural analyses of the composites and unreinforced aluminum alloy were performed to determine the strengthening mechanisms and plastic behavior that govern the structure-property relationships for this class of materials. Our results reveal that the flow stress of the composites does not depend strongly on strain rate if high rate data are included, while strain rate jump tests via instrumented nanoindentation indicate that the strain rate sensitivity exhibits similar behavior as the unreinforced matrix. The unreinforced alloy undergoes strain hardening at both quasi-static and dynamic strain rates, while the composites show strain softening at dynamic strain rates and elastic nearly-perfectly plastic behavior at quasi-static rates. Adiabatic shear band formation was evident in the composite samples during dynamic loading, whereas no shear banding was observed in the unreinforced alloy for the strain rates studied herein. The notion of adiabatic shear band toughness was adopted to identify the increased propensity to shear localization in the composites vis-a-vis the unreinforced material. An attempt is made to account for the effect of the boron carbide reinforcement size on the strengthening mechanism and overall plastic response for these metal matrix composites.
\end{abstract}

Keywords: metal matrix composites (MMCs); high strain rate behavior; adiabatic shear bands; strain rate effect. 


\section{Introduction}

Studies of aluminum alloys and their composites have been motivated in part by demands from the aerospace and defense industries to increase the specific strength and toughness of currently available materials. Inspection of the published literature reveals that there are a number of approaches that are currently being pursued, including alloying $[1,2]$, multilayer structures [3], and nanostructuring methods [4-6], to cite a few examples. As a matrix material in composite applications, aluminum is particularly attractive as a result of its formability, low weight and good corrosion resistance. Not surprisingly there are a number of recent investigations that aim to combine the benefits of a nanostructured matrix with ceramic reinforcements to form a metal matrix composite (MMC). As such, aluminum has been reinforced with carbides and oxides such as $\mathrm{Al} /$ carbon nanotubes (CNT), $\mathrm{Al} / \mathrm{SiC}, \mathrm{Al} / \mathrm{Al}_{2} \mathrm{O}_{3}, \mathrm{Al} / \mathrm{TiC}$, etc., [7-11]. Although most of these studies document enhancements in yield strength that are attributable to the fine grain size of the matrix, there are also consistent reports that plastic response is simultaneously degraded. An interesting concept proposed in recent years involves the design of a trimodal microstructure that contains both refined grains, either nanocrystalline (NC) or ultrafine grain (UFG), and less-refined coarse matrix grains in addition to the reinforcing media [12].

Of particular importance to this study was the development of a trimodal composite consisting of cryomilled Al 5083 and boron carbide particulates [13-15]. It exhibited improved plasticity at dynamic strain rates [16], improved yield strength [17] and high specific strength [18]. Boron carbide $\left(\mathrm{B}_{4} \mathrm{C}\right)$ is an attractive reinforcement material due to its good interfacial cohesion with aluminum [14, 17, 19-21], low density of $2.52 \mathrm{~g} / \mathrm{cm}^{3}$ [22], high melting point of $2445{ }^{\circ} \mathrm{C}$, and an elastic modulus of $460 \mathrm{GPa}$ [23].

The MMCs in the current investigation do not contain any coarse matrix grains, in contrast to the trimodal material described previously. Instead, the matrix material is fully UFG Al 5083 and is reinforced with particulate boron carbide. The previous trimodal studies have maintained a reinforcement size of $\sim 4-7$ microns, as the focus was on material processing and overall material performance [14, 15, 21, 24]. In the current study, the reinforcement size is reduced to the nanoscale with two reinforcement sizes 
used, approximately $40-50 \mathrm{~nm}$ and $500 \mathrm{~nm}$. As such, the reinforcement size effect is particularly examined in the present work. Previous works evaluated the effect of $500 \mathrm{~nm}$ and $\sim 40-50 \mathrm{~nm} \mathrm{~B}_{4} \mathrm{C}$ particles along with other relatively large size particles on the microstructure and/or mechanical behavior of Al-alloys [25, 26]. Also noted is that in this work, by eliminating additional variables such as matrix composition, processing, or variation of the reinforcing material, the role of the reinforcement size has been isolated. Reports have indicated improvements in wear resistance, yield strength and microstructural stability with decreasing particle size for other reinforcement media [27, 28] so enhanced material response is expected as well as variations in deformation mechanism [29].

Due to the recent development of this aluminum composite, there are many areas that require further investigation. For example, the elevated temperature response, bulkscale testing, and tensile properties all require additional study before these nanoreinforced composites are adequately characterized for commercial or industrial use. This paper, however, explores the difference in quasi-static and dynamic compressive loading behavior, and endeavors to explain the role of reinforcement size on the observed material properties. Additionally, a strengthening model is presented that takes into account the UFG matrix microstructure and the various reinforcement sizes. As adiabatic shear localization is observed under uniaxial compression, a simple model is used to provide a phenomenological explanation for its occurrence in the context of adiabatic shear band toughness.

\section{Experimental procedures}

\subsection{Materials processing}

The gas atomized aluminum Al 5083 (Valimet, Inc., Stockton, CA), -325 mesh particle size, had a material composition of Al-4.5 Mg-0.57 Mn-0.25 Fe in wt. \%. The aluminum powder was blended with $5 \mathrm{vol} . \% \mathrm{~B}_{4} \mathrm{C}$ powder with average particle sizes of $\sim 40 \mathrm{~nm}$ (fabricated by U.S. Army Armament Research, Development and Engineering Center, Picatinny, NJ) or $\sim 500 \mathrm{~nm}$ (HD20 B 4 C fabricated by HC Stark, Newton, MA) in

a V-blender for $12 \mathrm{~h}$. The blended powders were cryomilled for $12 \mathrm{~h}$ in liquid nitrogen in 
a modified Union Process 1S Svegvari attritor with a rotational velocity of 180 RPM, ball-to-powder ratio $=30: 1$ and $0.2 \mathrm{wt} \%$ stearic acid $\left(\mathrm{CH}_{3}\left(\mathrm{CH}_{2}\right)_{16} \mathrm{CO}_{2} \mathrm{H}\right)$ as a surfactant. Details regarding the cryomilling process can be found in previous publications [30, 31]. The cryomilled powders were hot-vacuum degassed at $500{ }^{\circ} \mathrm{C}$ for $20 \mathrm{~h}$ and dual mode dynamic (DMD) forged twice at $400{ }^{\circ} \mathrm{C}$. Sample identifications (IDs) and material conditions are summarized in Table 1. The Al-MMC with $40 \mathrm{~nm} \mathrm{~B} \mathrm{~B}_{4} \mathrm{C}$ particles is designated as $\mathrm{Al}-\mathrm{B}_{4} \mathrm{C}-1$, and $\mathrm{Al}-\mathrm{MMC}$ with $500 \mathrm{~nm} \mathrm{~B}_{4} \mathrm{C}$ particles is designated as $\mathrm{Al}-$ $\mathrm{B}_{4} \mathrm{C}-2$. A counterpart of ultra-fine grained Al 5083 alloy without reinforcing phase (NR$\mathrm{AL}$ ) was fabricated through an equivalent processing route, and characterized as a control.

Table 1

Summary of material conditions and sample IDs.

\begin{tabular}{l|c} 
Material & Boron Carbide Reinforcement Size (nm) \\
\hline $\mathrm{Al}_{\mathrm{B}} \mathrm{B}-1$ & $\sim 40$ \\
$\mathrm{Al}-\mathrm{B}_{4} \mathrm{C}-2$ & $\sim 500$ \\
NR-AL & N/A \\
\hline
\end{tabular}

\subsection{Microstructural analysis}

Microstructural analysis of the pre- and post-loading samples was performed using a JEOL-2100 ( $\mathrm{LaB}_{6}$ gun) transmission electron microscope (TEM) operated at $200 \mathrm{kV}$. TEM samples were prepared by first cutting a $0.5 \mathrm{~mm}$-thick sections of the desired sample, which were then formed into a $3 \mathrm{~mm}$ diameter disk using a Gatan sample cutter, and mounted to a 656 disc grinder (Gatan) to mechanically thin the samples to $\sim 70 \mu \mathrm{m}$. The samples were then subjected to further thinning on a 656 dimple grinder (Gatan), before finally being transferred to a Gatan 691 precision ion polisher system (PIPs) for final thinning to electron transparency.

TEM bright field and dark field images were used in conjunction with ImageJ to assess the grain size and other microstructural features prior to and following dynamic and quasi-static testing. Optical microscopy was used in conjunction with scanning electron microscopy (SEM) to provide analysis of the surface morphology of the samples before and after testing.

Post-loading samples were recovered and polished for nanoindentation following a three-step procedure using increasingly fine polishing papers: 1200 grit Leco SiC paper, 
$0.5 \mu \mathrm{m} \mathrm{SiC}$ paper, and finally $0.05 \mu \mathrm{m} \mathrm{Al}_{2} \mathrm{O}_{3}$ particulate solution on a Leco polishing cloth.

\subsection{Mechanical Testing}

Quasi-static tests were performed on all samples using an MTS Landmark Servo Hydraulic Test System at a constant strain rate of $\sim 1 \times 10^{-3} \mathrm{~s}^{-1}$. The system is equipped with self-alignment features to maintain parallelism and perpendicularity during testing. The dimensions of the specimens for quasi-static testing were $\sim 2.5 \times 2.5 \times 5 \mathrm{~mm}$. The loading faces and sides of the samples were polished before testing to ensure even contact and to assist in post-loading examination. Loading surfaces were lubricated to reduce friction interactions between the sample and the loading platens (MTS 643 Compression Platens). The strain rate was controlled via modulation of the crosshead speed.

Dynamic (high strain rate) tests were performed using a Kolsky bar, also known as a split Hopkinson pressure bar (SHPB), system. The technical specifications regarding its use, data processing, setup and sample preparation can be found in a standard handbook [32], though a basic description of the system is provided here for convenience. The system consists of two coaxial steel bars made of the same material, also called the input/output bars, and of the same diameter, which operate within their elastic limit. The sample of interest is placed between the bars and lubricant is placed on both loading faces so as to reduce friction effects such as sample barreling. A gas gun is loaded with a shorter bar, also called the bullet or projectile/striker bar, again of the same diameter and material as the two loading bars. Modulation of the strain rate is controlled through the use of pulse-shapers and by increasing or decreasing the pressure of the gas gun. When launched, the striker bar collides with the first loading bar (input bar), and the stress wave is transmitted to the sample. The stress wave continues through the sample and into the next loading bar (the output bar). Additionally, some of the wave is reflected at the sample-output bar interface and travels back into the input bar. Two strain gauges located in the middle of the input and output bars respectively, capture the behavior of the bars and the signals are transmitted to an oscilloscope. Post-processing of the initial, transmitted, and reflected wave signals allows for determination of the stress and strain 


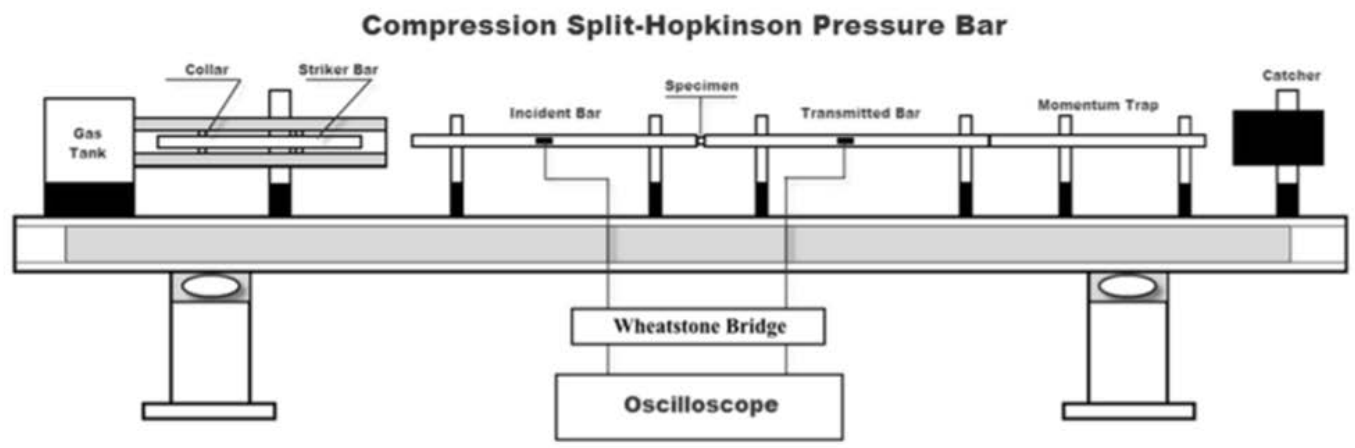

Fig. 1. (1.5-column)

A schematic representation of the Kolsky bar setup used in this investigation for dynamic compression testing.
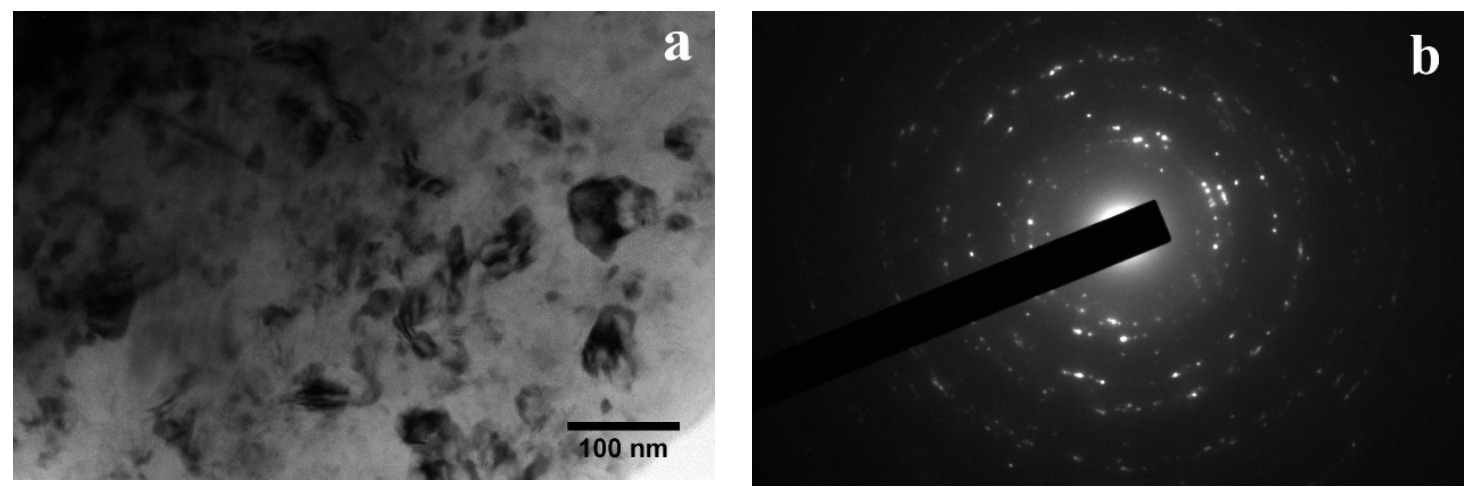

Fig. 2. (2-column)

Representative TEM bright field image of $\mathrm{Al}_{-} \mathrm{B}_{4} \mathrm{C}-2$ (a) with the corresponding dark field image (b) demonstrating the ring-like pattern indicative of a polycrystalline sample. While the ring-like pattern is evident in (b), there are a large number of discrete spots due to strong diffraction of a few grains. The TEM specimen is taken from a post-dynamic loading sample.

response of the specimen at high strain rates. A schematic for the Kolsky bar system is depicted in Fig. 1.

The samples prepared for high strain rate testing measured $\sim 2.5 \times 2.5 \times 2.0 \mathrm{~mm}$, with the loading direction parallel to the $2 \mathrm{~mm}$ dimension (the gage section). Strain rates ranged from $\sim 4000 \mathrm{~s}^{-1}$ to $\sim 5000 \mathrm{~s}^{-1}$ for the Al-MMCs and $\sim 6000 \mathrm{~s}^{-1}$ to $\sim 7000 \mathrm{~s}^{-1}$ for the unreinforced Al 5083 with no prescribed strain in either condition. The higher imposed strain rate for the unreinforced $\mathrm{Al}$ samples was a result of using the same loading pressure as was used for the Al-MMCs. 
An instrumented nanoindenter (Agilent G-200) was used to evaluate hardness values, as well as to derive the strain rate sensitivity (SRS). A series of 10 indents were performed for each condition in order to illuminate any statistically relevant trends. 20 indents consisting of three strain rates $0.05,0.007$, and $0.001 \mathrm{~s}^{-1}$ were performed with an initial indentation depth of $1100 \mathrm{~nm}$, and a final depth of $2000 \mathrm{~nm}$ on the as-received samples to obtain the SRS. It is assumed that strain rate hardening follows the popular power law trend, and as such, SRS is the slope of the double logarithmic plot of hardness versus the indentation strain rate. Details for using nanoindentation to derive SRS values can be found in Ref. [33].

\section{Experimental results}

\subsection{Microstructural analysis}

The microstructures of $\mathrm{Al}-\mathrm{B}_{4} \mathrm{C}-1, \mathrm{Al}-\mathrm{B}_{4} \mathrm{C}-2$, and NR-AL were analyzed using a combination of SEM and TEM techniques. A representative TEM bright field (BF) image is shown in Fig. 2 (a) for $\mathrm{Al}_{-}-\mathrm{B}_{4} \mathrm{C}-2$, along with the selected area electron diffraction (SAED) pattern (Fig. 2 (b)). The TEM specimen was taken from a dynamically compressed sample. It should be noted that the as-consolidated specimen does not show significant difference from the mechanically loaded one. The SAED has a ring-like pattern indicating a polycrystalline Al matrix grain structure, along with a large number of discrete diffraction spots from oriented grains. The bright field image in Fig. 3 (a) is from $\mathrm{Al}-\mathrm{B}_{4} \mathrm{C}-1$ and shows grains with a large number of dislocations. Fig. 3 (c) shows the corresponding dark field image with the diffraction from the $\{012\}$ plane of $\mathrm{B}_{4} \mathrm{C}$ highlighted, as shown in Fig. 3 (b). Analysis of the boron carbide reinforcement indicated that particles were on the order of $40-50 \mathrm{~nm}$ in diameter. Again the TEM specimen was prepared from a dynamically compressed sample, which shows little difference from the as-consolidated condition.

The microstructure of the unreinforced $\mathrm{Al}$ alloy was characterized, and some representative micrographs are provided in Fig. 4. The microstructure for the postdynamic loading NR-AL sample is shown in Fig. 4 (a) and is indicative of the larger yet submicron grains that are present in the NR-AL sample both pre- and post-loading (pre- 
loading images are not shown here), the provided arrows highlight grain boundaries. Figs. 4 (b) and 4 (d) indicate the second-phase particles that presumably formed during cryomilling and are on the order of $10 \mathrm{~nm}$. The diffraction spots circled in Fig. 4 (c) indicate the diffraction spots that were highlighted to produce the dark field image.
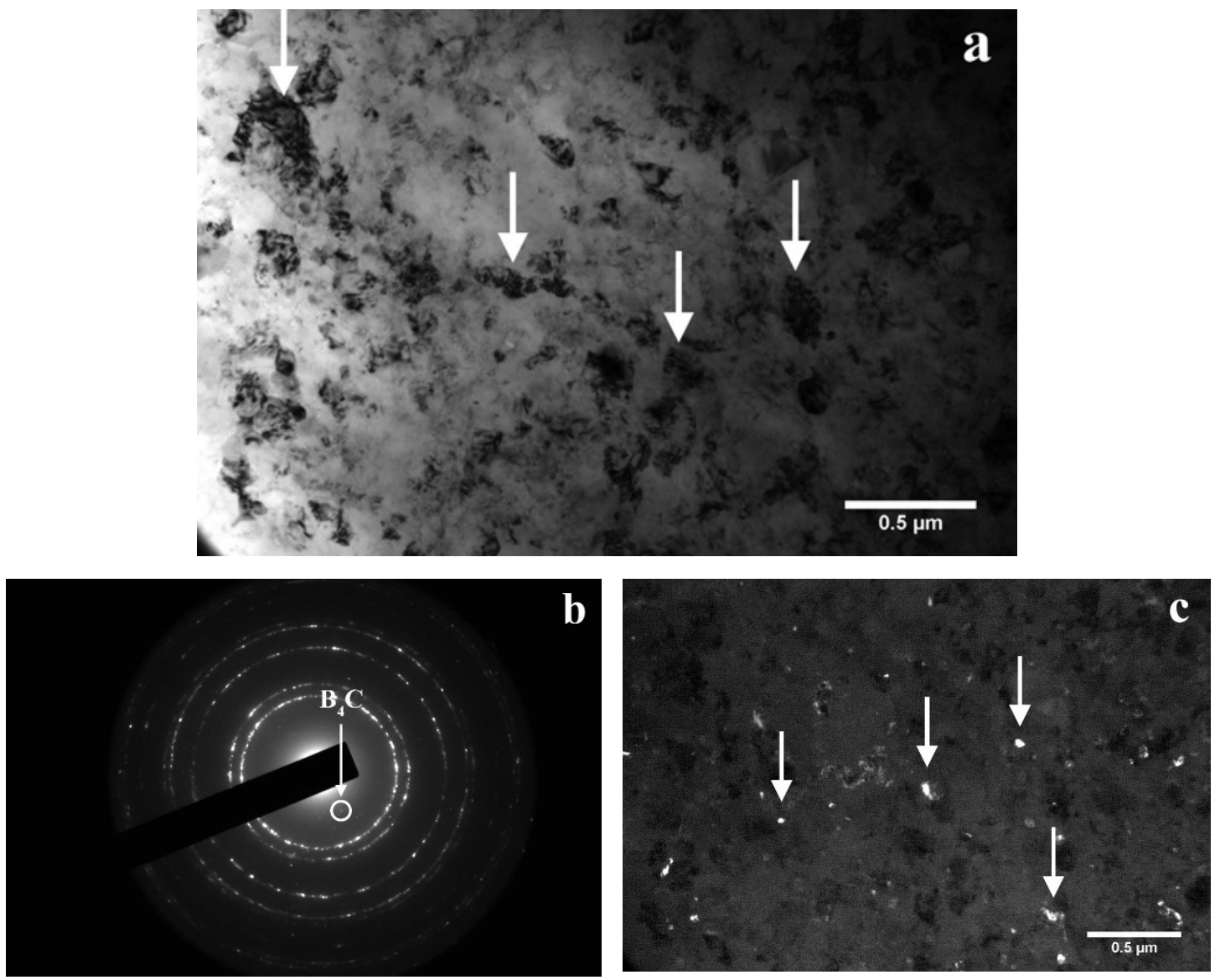

Fig. 3. (2-column)

TEM images of Al- $\mathrm{B}_{4} \mathrm{C}-1$; the bright field image (a) shows that grains are highly deformed with many dislocations, and without well-defined grain boundaries. The SAED (b) indicates the $\mathrm{B}_{4} \mathrm{C}$ diffraction spot isolated to produce the dark field image (c). The reinforcing particles are found to be on the order of $40-50 \mathrm{~nm}$.

Though close to the aluminum diffraction ring the spots lie just outside it, and the small size of the particles is below the limits of the grain refinement performed on the samples. Based on the d-spacing and the findings of others working on cryomilled $\mathrm{Al}$ in liquid nitrogen $[2,34]$, we propose that these are AlN particles. It is also possible for the Almatrix to form oxide during processing. It should be noticed that we did not observe the 
intermetallic phase reported by other investigators on AA-5083, such as the $\beta$-phase $\left(\mathrm{Al}_{3} \mathrm{Mg}_{2}\right)[35]$.
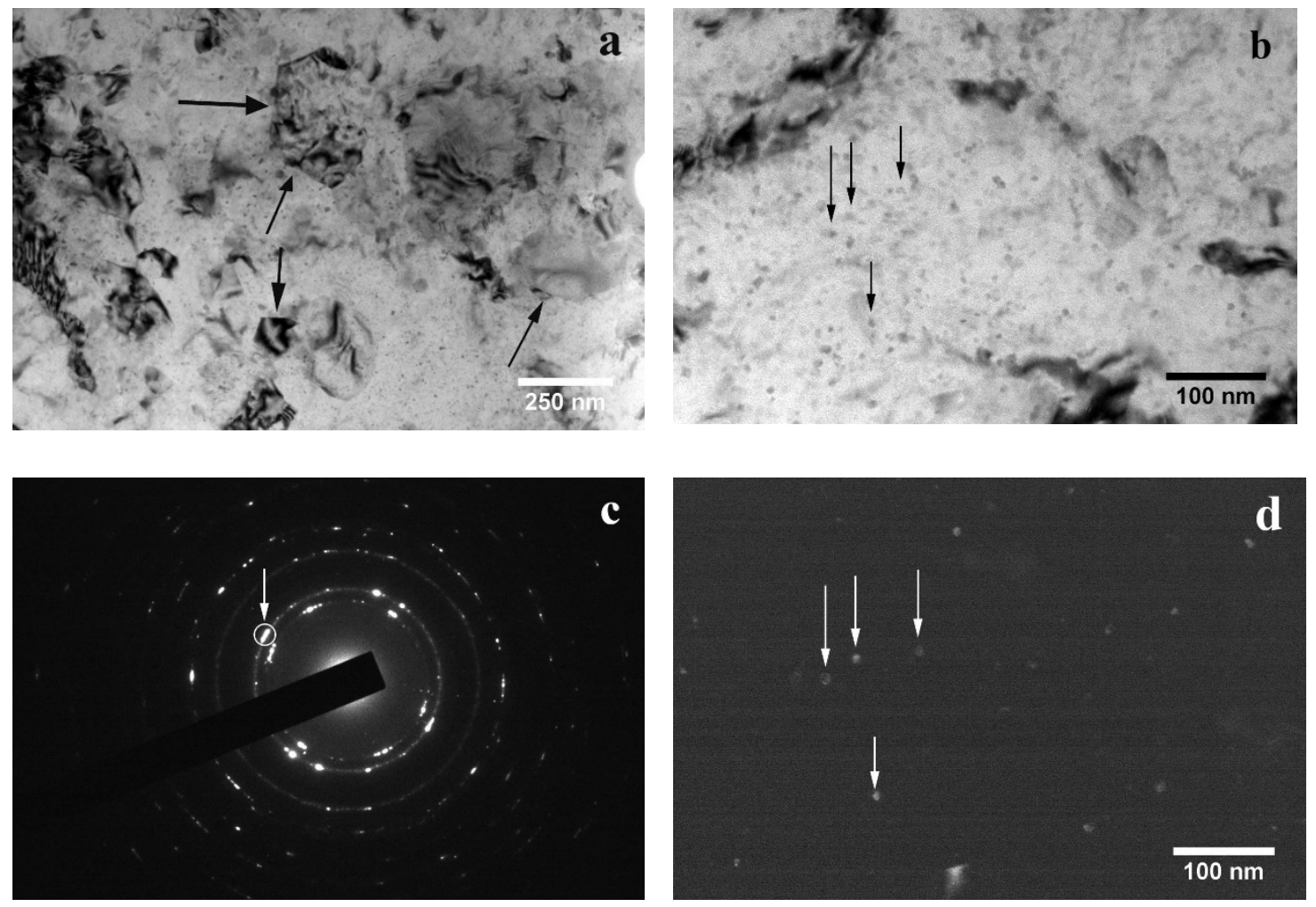

Fig. 4. (2-column)

The microstructure of NR-AL post-loading (a) exhibits grains on the order of $200-250 \mathrm{~nm}$, approximately $100 \mathrm{~nm}$ larger than either composite sample. Second phase particles, possibly nitrides and oxides presumably formed during cryomilling are highlighted in the bright field (b) and dark field (d). Analysis of the particles reveals that they are approximately $10 \mathrm{~nm}$ in diameter. Their size combined with a d-spacing similar to that of aluminum nitride (c) makes it likely that these are AlN and/or oxide particles formed during cryomilling, such dispersoids have been found previously [2].

This can be understood as follows. First, the occurrence of the intermetallic phase was observed after extended artificial aging at $175^{\circ} \mathrm{C}$ and the $\beta$-phase has a plate/needle like shape. The fabrication of the materials in this work involves $500^{\circ} \mathrm{C}$ degassing and $400^{\circ} \mathrm{C}$ forging, both considerably above the solvus line of the Al-Mg binary phase diagram. In other words, the intermetallic phase would have no opportunity to precipitate out. 
a
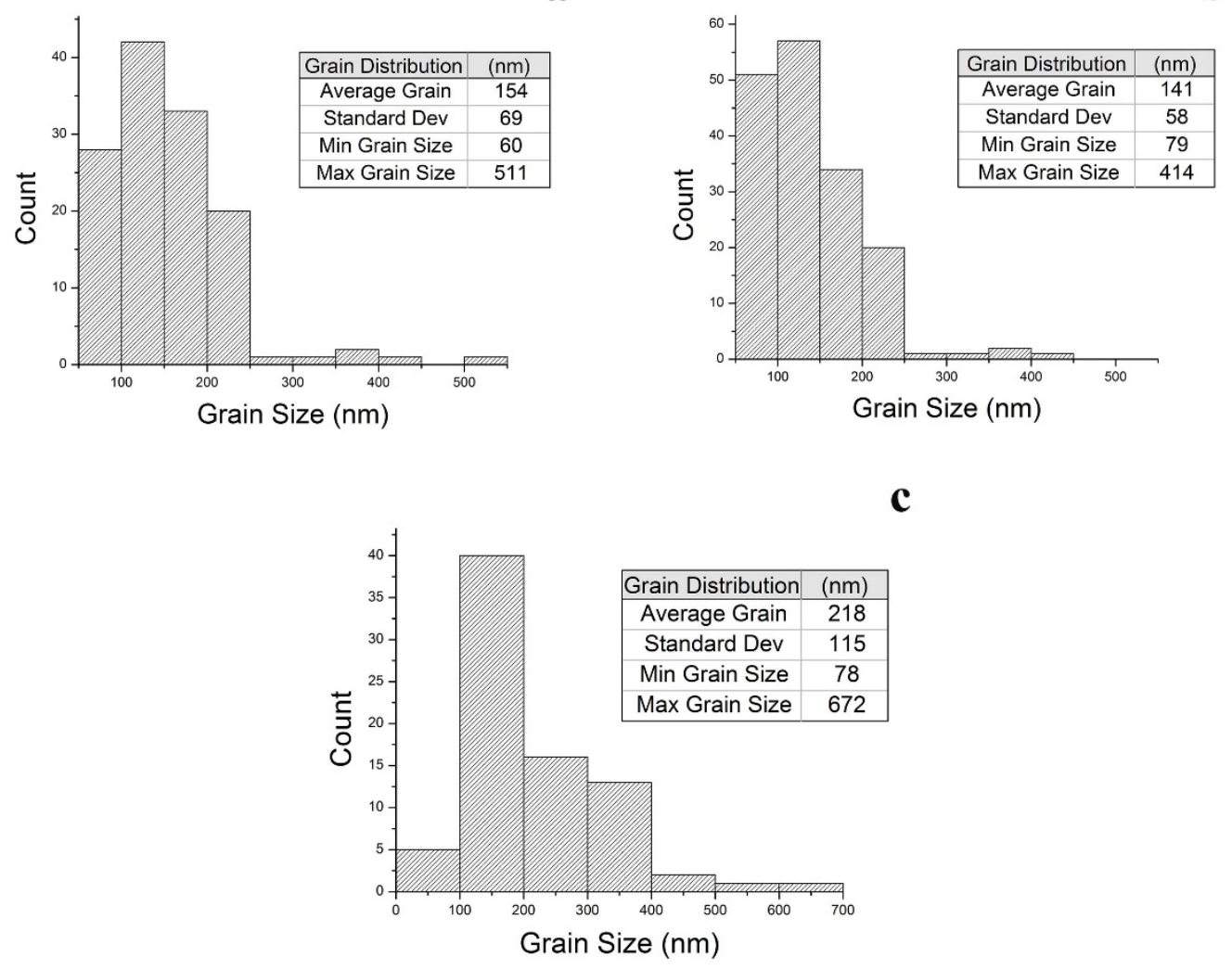

Fig. 5. (2-column)

Grain size distribution of matrix grains in $\mathrm{Al}_{-} \mathrm{B}_{4} \mathrm{C}-1$ (a), $\mathrm{Al}-\mathrm{B}_{4} \mathrm{C}-2$ (b), and NR-AL (c). The distribution and average grain size exhibited in (a) and (b) closely match those from ref. [28], while the average and maximum grain size of NR-AL indicates that some grain growth likely occurred during processing.

Transmission electron micrographs from the specimens were used to statistically analyze grain sizes of the three samples and the grain size histograms are shown in Fig. 5. After an analysis of 129 grains from the TEM images, the histogram of the grain size of the Al- $\mathrm{B}_{4} \mathrm{C}-1$ matrix is shown in Fig. 5 (a) where the average value was found to be 154 $\mathrm{nm}$. Similar analyses were performed on the other two materials (Figs. 5 (b-c)) and the average grain sizes were found to be $141 \mathrm{~nm}$ for Al- $\mathrm{B}_{4} \mathrm{C}-2$ and $218 \mathrm{~nm}$ for NR-AL. These grain sizes agree well with those provided in [17], where the average grain size of the UFG Al matrix with micron sized boron carbide reinforcement was found to be $156 \mathrm{~nm}$.

\subsection{Mechanical Properties}




\subsubsection{Dynamic and quasi-static compression tests}

In this section the results of the quasi-static (QS) and dynamic (DY) compression tests for the three aluminum-based materials are presented. Fig. 6 shows the representative quasi-static (a) $\left(\begin{array}{lllll}\sim 1.0 & \left.\times 10^{-3} \mathrm{~s}^{-1}\right)\end{array}\right)$ and dynamic (b) $\left(\sim 4.0 \times 10^{3} \mathrm{~s}^{-1}\right)$ compression curves for $\mathrm{Al}-\mathrm{B}_{4} \mathrm{C}-1, \mathrm{Al}-\mathrm{B}_{4} \mathrm{C}-2$, and NR-AL. The yield strengths for the composite samples under both quasi-static and dynamic conditions are similar with yield occurring around $850-900 \mathrm{MPa}$. These values are in contrast to the unreinforced alloy which exhibits a yield strength around $600 \mathrm{MPa}$, indicating a 30\% improvement in yield strength for the Al composites. Since all three samples underwent the same powder processing method, the difference in mechanical properties should be due to the inclusion of the boron carbide particles, and their effect on the microstructure. The detailed discussion of the strengthening mechanisms is deferred to a later section.

Comparison of the strain experienced by the composites also exhibits similarities, with unloading occurring at a value of approximately $20 \%$ true strain under dynamic compression for $\mathrm{Al}-\mathrm{B}_{4} \mathrm{C}-1$, and at a slightly higher value for $\mathrm{Al}-\mathrm{B}_{4} \mathrm{C}-2$. Under quasi-static loading $\mathrm{Al}-\mathrm{B}_{4} \mathrm{C}-1$ experienced failure at approximately $20 \%$ true strain before reaching the prescribed strain of $30 \%$. The unreinforced alloy did not form cracks under dynamic loading, while the dynamically loaded composite samples started to develop shear localization and subsequently cracks that can be seen under SEM investigation (Fig. 7). The stress drop at the end of the curves in Fig. 6 (b) is due to unloading of the samples, and not necessarily failure of the material.

The unreinforced aluminum alloy consistently underwent comparable or increased plasticity without failure as compared to both $\mathrm{Al}-\mathrm{B}_{4} \mathrm{C}-1$ and $\mathrm{Al}-\mathrm{B}_{4} \mathrm{C}-2$. Under quasi-static compression NR-AL underwent $25 \%$ true strain without failure, while dynamic loading led to a final strain of $40 \%$ and though the sample still did not fail, and it instead underwent significant inhomogeneous deformation as can be seen in Fig. 7 (a). The plastic behavior of the samples differed as well, with NR-AL undergoing moderate, and minor strain hardening during quasi-static and dynamic loading respectively while the composites underwent strain softening during dynamic deformation. During quasi-static deformation however, $\mathrm{Al}-\mathrm{B}_{4} \mathrm{C}-1$ exhibited an elastic-nearly perfect plastic response after yielding (Fig. 6 (a)) with slight yet distinct flow softening. 

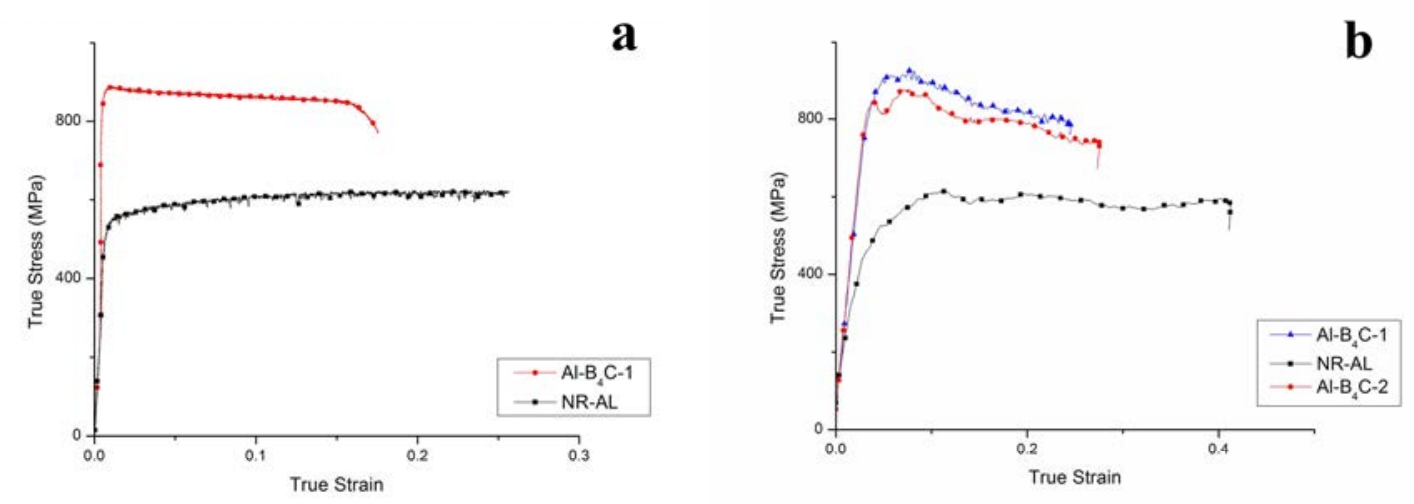

Fig. 6. (2-column)

Representative true stress - true strain results for quasi-static (a) and dynamic (b) compression of the aluminum alloy and composites. The non-reinforced alloy exhibits strain hardening at quasi-static and dynamic strain rates though the strain hardening is much reduced at dynamic rates due to thermal softening. Composite samples undergo strain softening at both strain rates, though softening is greatly diminished during quasi-static testing and may be considered elastic-nearly perfect plastic. Quasi-static tests were stopped at a prescribed strain of $0.3(\sim 30 \%)$, and the composite samples failed during testing. Dynamic tests had no prescribed strain and the stress drop at the end is due to sample unloading, no failure was observed.

Shear banding-like behavior was observed in the two composite materials, though only under dynamic conditions. In both MMCs the shear bands were localized to two conjugate shear planes as highlighted in Fig. 7 (c). Both localized plasticity and cracking was observed along the shear bands, with one sample often exhibiting both forms of deformation. Due to the localized nature of the shear bands and the time scale of their formation, they can be classified as adiabatic shear bands (ASB) [36]. Under quasi-static loading, Al- $\mathrm{B}_{4} \mathrm{C}-1$ fractured along the plane of maximum shear stress, however no localized deformation was observed, and the fracture appears to be of semi-brittle type as indicated by Fig. 8 . 

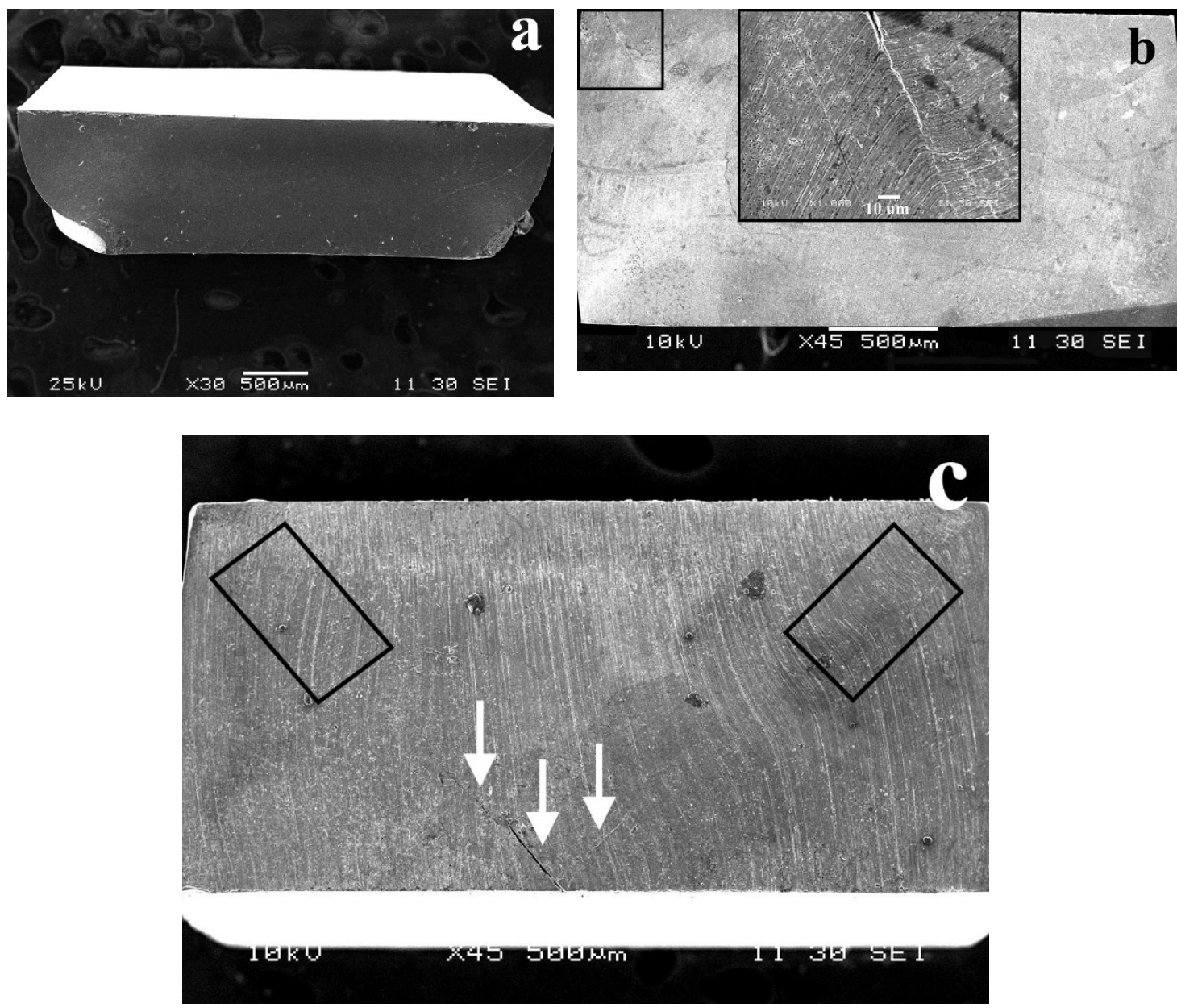

Fig. 7. (2-column)

SEM images of (a) NR-AL, (b) Al- $\mathrm{B}_{4} \mathrm{C}-1$ and (c) Al- $\mathrm{B}_{4} \mathrm{C}-2$ after dynamic compression. No localized shearing is observed in NR-AL, while both composites exhibit localized plasticity along shear bands. Enlarged inset in (b) shows significant localized shear and crack formation. Highlighted sections of (c) indicate the conjugate shear planes that develop during dynamic deformation. 


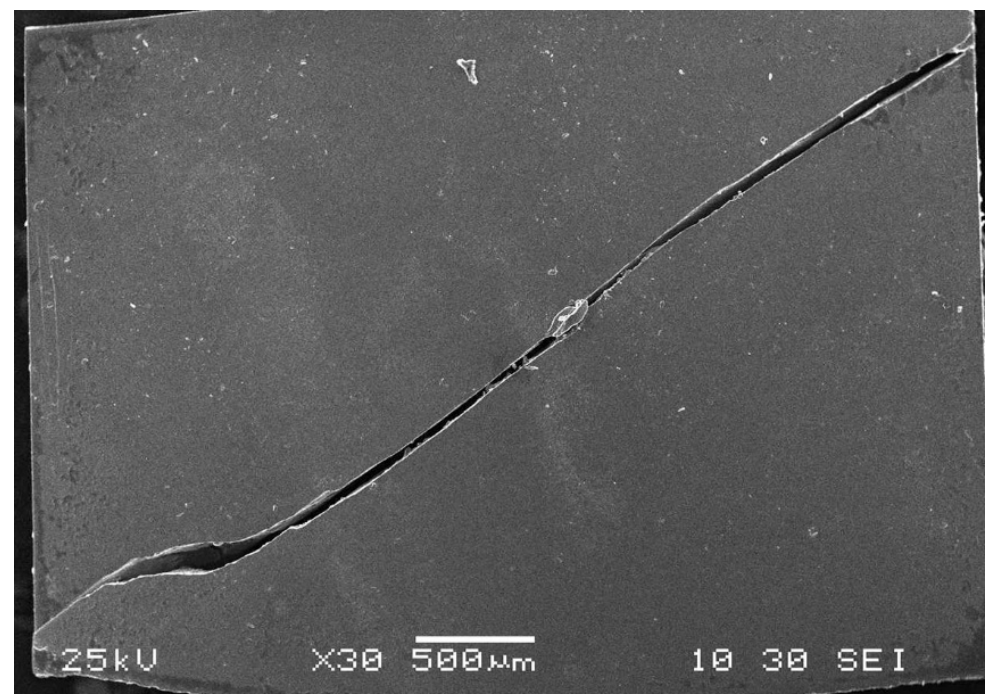

Fig. 8. (1.5-column)

SEM image of quasi-statically loaded $\mathrm{Al}-\mathrm{B}_{4} \mathrm{C}-1$ exhibiting the brittle fracture the sample underwent without developing the localized plasticity observed in the dynamically deformed composite.

\subsubsection{Nanoindentation}

Nanoindentation hardness and strain-rate-jump tests were performed on the three aluminum-based materials to provide further insight into their mechanical properties. The Vickers hardness test was used to provide additional confirmation of the yield strengths found for $\mathrm{Al}-\mathrm{B}_{4} \mathrm{C}-1, \mathrm{Al}-\mathrm{B}_{4} \mathrm{C}-2$, and $\mathrm{NR}-\mathrm{AL}$ with values of $938 \mathrm{MPa}, 909 \mathrm{MPa}$, and 644 $\mathrm{MPa}$ respectively. These values compare favorably with those found during compression tests, as can be seen in Table 2. The Vickers hardness were converted to the yield strength through the Tabor law, and the most commonly used form is $\mathrm{VHN}=3 \sigma_{\mathrm{y}}$, and VHN is the Vickers hardness number.

Strain-rate-jump tests were subsequently performed at increasing strain rates, to determine the influence of strain rate on material performance. The results are shown in Fig. 9, which is the double logarithmic plot of nanoindentation hardness versus the indentation strain rate. It was found that the SRS values of the materials were very similar, all existing within an order of magnitude, though the SRS of $\mathrm{Al}_{-}-\mathrm{B}_{4} \mathrm{C}-1$ and NRAL were slightly higher than that of $\mathrm{Al}_{-} \mathrm{B}_{4} \mathrm{C}-2$. It should be noted that in Fig. 9, the high 


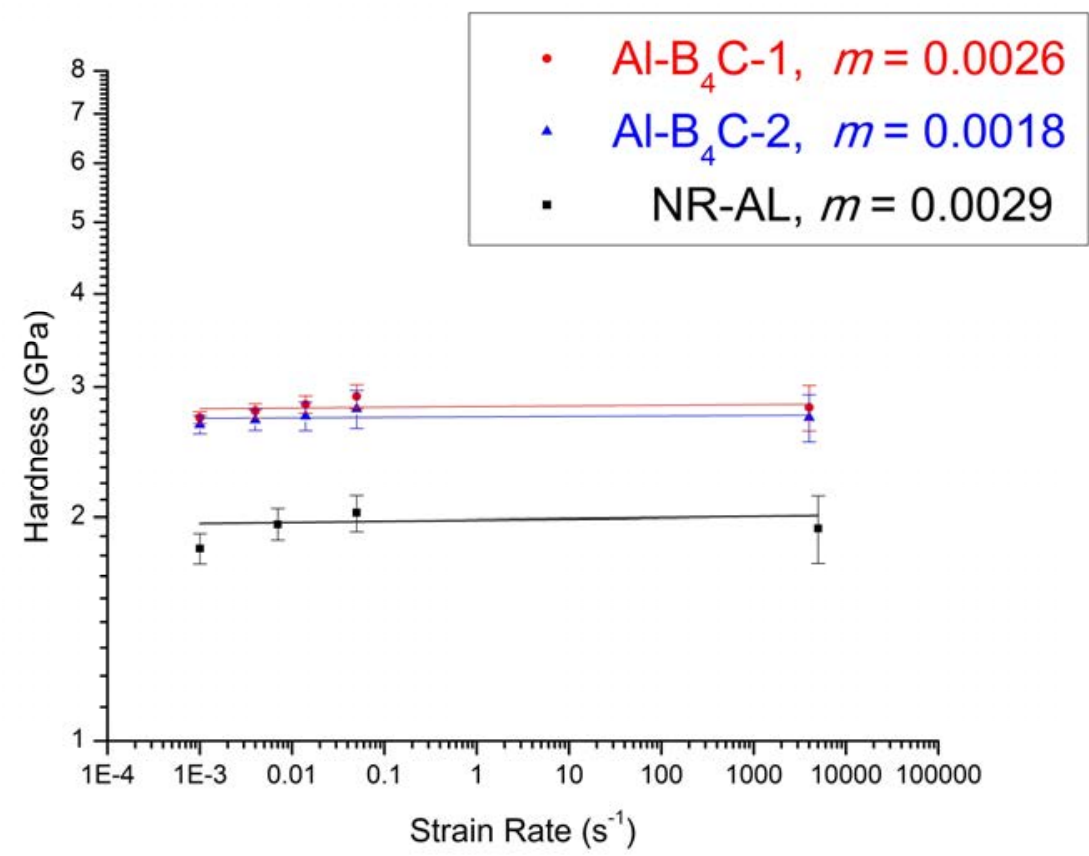

Fig. 9. (1.5-column)

Strain rate sensitivity of the aluminum alloy and composites indicating low rate dependence. The high strain rate data were collected from dynamic compression, while the low strain rate data points were a result of strain-rate jump tests performed during nanoindentation.

strain rate data points from the Kolsky bar experiments are also included. The effect of this practice is discussed in the next section.

\section{Discussion}

In this section we provide an in-depth discussion on the experimental results presented in the previous section. Focus will be on the strengthening mechanisms, the plastic deformation mechanism and the various factors affecting them.

First of all, it should be noticed that the current study focused on three different materials, $\mathrm{Al}-\mathrm{B}_{4} \mathrm{C}-1, \mathrm{Al}-\mathrm{B}_{4} \mathrm{C}-2$ and $\mathrm{NR}-\mathrm{AL}$, which exhibit some similarities in their microstructure due to the same cryomilling and DMD (dual mode dynamic) forging processes that all three materials underwent. An important feature of the microstructure is grain size, as grain size refinement is the single largest contributor to the strength of the materials, which follows the Hall-Petch relationship [37]. In addition to the elements in 
Table 2

Mechanical properties of the aluminum alloys and composites, with coarse grained Al 5083 included for comparison. The coarse-grained aluminum value [28] is used in the calculation of the Hall-Petch strengthening.

\begin{tabular}{ccccc}
\hline Material & QS 0.2\% Stress $(\mathrm{MPa})$ & DY 5\% Offset $(\mathrm{MPa})$ & NI Hardness $/ 3(\mathrm{MPa})$ & SRS $(\mathrm{m})$ \\
\hline $\mathrm{Al}-\mathrm{B}_{4} \mathrm{C}-1$ & $860 \pm 15$ & $900 \pm 10$ & $938 \pm 23$ & 0.0026 \\
$\mathrm{Al}-\mathrm{B}_{4} \mathrm{C}-2$ & - & $850 \pm 15$ & $909 \pm 16$ & 0.0018 \\
$\mathrm{NR}-\mathrm{Al}$ & $572 \pm 6$ & $575 \pm 23$ & $645 \pm 29$ & 0.0029 \\
$\mathrm{CG}-\mathrm{Al}$ & 124 & - & - & - \\
\hline
\end{tabular}

Notes:

QS: quasi-static loading

DY: dynamic loading

Al 5083-B4C-1: $\mathrm{B}_{4} \mathrm{C}$ average particle size: $\sim 40 \mathrm{~nm}$;

Al 5083-B4C-2: $\mathrm{B}_{4} \mathrm{C}$ average particle size: $\sim 500 \mathrm{~nm}$;

NR-Al 5083: Non-reinforced Al 5083 processed by cryomilling and consolidation;

CG-Al 5083: Coarse-grained Al 5083 alloy;

NI Hardness/3: Nanoindentation divided by a constraint factor of 3 in the sense of Tabor rule;

SRS (m): Strain rate sensitivity following power law rate dependence.

the alloy ( $4-5 \%$ magnesium, $\sim 0.5 \%$ manganese and trace iron) the cryomilling process also introduces oxygen and nitrogen that can react with other elements to create secondary nitrides and oxides within the matrix [21]. These dispersoids interact with dislocations in the samples leading to additional strengthening.

In order to account for the transfer of load to the boron carbide a modified shear lag model was used. The differences in the coefficient of thermal expansion and elastic modulus between the matrix and reinforcement and their role in dislocation formation is discussed in the following sections. It has been predicted that decreasing the size of reinforcements leads to an increase in dislocation density [38], so it would be expected that $\mathrm{Al}-\mathrm{B}_{4} \mathrm{C}-1$ and $\mathrm{Al}-\mathrm{B}_{4} \mathrm{C}-2$ would contain more dislocations overall, even if there are fewer dislocations around each particle compared to composites with larger micron-sized reinforcements. Additionally, the Orowan strengthening resulting from the reinforcing particles and second phase nitrides/oxides is considered, and the dislocation strengthening is treated in a quadratic format. Finally, the influence of the boron carbide reinforcement and processing method on the plastic deformation of the samples is discussed. In particular, the occurrence of adiabatic shear bands in the composite is dealt with in detail in the context of adiabatic shear band toughness.

\subsection{Grain size strengthening via Hall-Petch effect}


Cryomilling is used to reduce the original $\mathrm{Al} 5083$ powder particles down to 100 - $200 \mathrm{~nm}$ grains after consolidation. The Hall-Petch relationship dictates the strengthening of the ultrafine-grain aluminum matrix, which accounts for the majority of the final strength of the composite. The Hall-Petch relationship states that the yield strength scales linearly with the inverse square root of the grain size, and is in the form $[21,39,40]$,

$$
\Delta \sigma_{H P}=\sigma_{0}+k_{y} d^{-1 / 2},
$$

where $\Delta \sigma_{H P}$ is the yield strength improvement after taking into account grain size strengthening; $\sigma_{0}$ is the frictional stress (lattice friction, or the yield strength of coarsegrain material), $d$ is the grain size, and $k_{y}$ is a constant of .22 MPa $\sqrt{m}$ [41] for $\mathrm{Al} 5083$. In the case of $\mathrm{Al} 5083 \sigma_{0}$ is $\sim 124 \mathrm{MPa}$, which includes the strengthening from solute atoms [42], the average grain size was $154 \mathrm{~nm}$ for $\mathrm{Al}-\mathrm{B}_{4} \mathrm{C}-1,141 \mathrm{~nm}$ for $\mathrm{Al}-\mathrm{B}_{4} \mathrm{C}-2$ and $218 \mathrm{~nm}$ for NR-AL. Using these values, a grain refinement-based yield strength improvement of $\Delta \sigma_{н P}=560 \mathrm{MPa}$ was calculated for the $\mathrm{Al}-\mathrm{B}_{4} \mathrm{C}-1,586 \mathrm{MPa}$ for Al- $\mathrm{B}_{4} \mathrm{C}-2$, and $471 \mathrm{MPa}$ for NR-AL. Compared to the strength values of the three materials listed in Table 2, all the Hall-Petch contributions fall short of the experimental yield strength values, suggesting that additional strengthening mechanisms should be considered to reconcile the experimental results and theoretical predictions.

\subsection{Composite Strengthening}

Orowan strengthening is either not significant or is entirely invalid for micronsized particulate composites due to the large interparticle spacing [43] and their large size in comparison to the matrix grains. So while $\mathrm{Al}-\mathrm{B}_{4} \mathrm{C}-2$ with $\mathrm{B}_{4} \mathrm{C}$ size $\sim 500 \mathrm{~nm}$ will not undergo significant Orowan strengthening from its reinforcement particles, $\mathrm{Al}-\mathrm{B}_{4} \mathrm{C}-1$ will, as the $40 \mathrm{~nm}$ particles are smaller than the average matrix grain size $(\sim 154 \mathrm{~nm})$. Additionally, the microstructure of these cryomilled materials, both the alloy and composites, contain secondary particles such as nitrides and oxides that also provide Orowan strengthening $[2,21]$. There have been a number of treatments on the Orowan 
mechanism depending on the specific details of the various models adopted with some earlier models summarized in the book edited by Argon [44]. The theoretical value of the Orowan strengthening can be estimated by an articulated model proposed by Brown and Ham[45],

$$
\Delta \sigma_{O r}=\frac{1.25 G_{m} b}{\pi \sqrt{1-v}} \ln \frac{(\bar{d} / b)}{\bar{\lambda}},
$$

where $\Delta \sigma_{O r}$ is the yield strength increase due to Orowan strengthening, $G_{m}$ is the shear modulus of the matrix taken as $27 \mathrm{GPa}$ [21], $b$ is the Burgers vector of the matrix, and $v$ is Poisson's ratio of 0.33 . The mean dispersoid size, $\bar{d}$ and the mean inter-particle distance $\bar{\lambda}$ are given by $\bar{d}=\sqrt{2 / 3} \cdot d$ and $\bar{\lambda}=\bar{d}\left(\sqrt{\pi / 4 V_{p}}-1\right)$ respectively where $d$ is the particle size and $V_{p}$ is the volume fraction of the $\mathrm{B}_{4} \mathrm{C}$ particulate or nitride/oxide. In $\mathrm{Al}$ $\mathrm{B}_{4} \mathrm{C}-1$ the value of $d$ was taken as $40 \mathrm{~nm}$, and $V_{p}$ as $5 \%$ as indicated from the processing parameters, while the nitrides and oxides were estimated as $10 \mathrm{~nm}$ and $V_{p}$ as $0.5 \%$ [2]. To account for the load transferred to the reinforcing particles Nardone and Prewo's modified shear lag model was used, with the particles considered to be equiaxed yielding $[46,47]$,

$$
\Delta \sigma_{l}=0.5 V_{p}
$$

where $V_{p}$ is the volume fraction of the reinforcing particles.

The final strengthening mechanisms to consider are those that result from a difference in material parameters between the matrix and reinforcement, namely elastic modulus and coefficient of thermal expansion (CTE) differences. Recent published studies related to UFG and NC Al MMCs [48] have indicated that CTE mismatch does not provide a significant contribution to material strength. Taken in conjunction with 
Lloyd's analysis that the critical CTE misfit strain cannot generally be reached for particles $<100 \mathrm{~nm}$ [49] it was determined that CTE mismatch induced dislocations should be excluded. Geometrically necessary dislocations due to elastic modulus mismatch however still play a role, and can be estimated using the equation [50],

$$
\Delta \sigma_{G N D}=k G_{m} b \sqrt{\frac{8 V_{p} \varepsilon_{y}}{b d}}
$$

where $k$ is a constant, in this case $1.25, \varepsilon_{y}$ is the yield strain taken as $0.2 \%$ or 0.002 . A quadratic treatment $[24,51]$ was used to consolidate the various dislocation mechanisms,

$$
\Delta \sigma_{\text {dis }}=\sqrt{\left(\Delta \sigma_{O r}^{I}\right)^{2}+\left(\Delta \sigma_{O r}^{I I}\right)^{2}+\left(\Delta \sigma_{G N D}\right)^{2}}
$$

where $\Delta \sigma_{O r}^{I}$ is the Orowan strengthening due to nitride and oxide particulates and $\Delta \sigma_{O r}^{I I}$ is the Orowan strengthening due to the nanoscale reinforcement in $\mathrm{Al}-\mathrm{B}_{4} \mathrm{C}-1$. The strengthening in $\mathrm{Al}-\mathrm{B}_{4} \mathrm{C}-1$ can then be summed as,

$$
\sigma_{y}=\Delta \sigma_{\text {dis }}+\Delta \sigma_{H P}+\Delta \sigma_{l} \text {. }
$$

The individual contributions come out as $\sigma_{y}=241 \mathrm{MPa}+684 \mathrm{MPa}+17 \mathrm{MPa}=942 \mathrm{MPa}$ for $\mathrm{Al}-\mathrm{B}_{4} \mathrm{C}-1$. In $\mathrm{Al}-\mathrm{B}_{4} \mathrm{C}-2$ there is no Orowan contribution from the boron carbide, and so it is somewhat lower as $\sigma_{y}=135 \mathrm{MPa}+710 \mathrm{MPa}+17 \mathrm{MPa}=862 \mathrm{MPa}$. Finally, for the unreinforced alloy, the only dislocation mechanism is due to secondary nitrides and oxides and the estimated yield strength is $\sigma_{y}=133 \mathrm{MPa}+595 \mathrm{MPa}=728 \mathrm{MPa}$.

The results of the above calculations and the contributing mechanisms are summarized in Table 3. The estimates resulting from the treatment provided here closely match the experimentally obtained values, though unreinforced alloy strength is considerably overestimated with this method, which assumes that the underlying 
mechanisms are additive, which clearly they are not. The experimental and calculated values of the yield strength also indicate an increased yield strength for $\mathrm{Al}_{-} \mathrm{B}_{4} \mathrm{C}-1$ reinforced with the smaller $40 \mathrm{~nm}$ boron carbide as compared to $\mathrm{Al}-\mathrm{B}_{4} \mathrm{C}-2$. The reduction of particulate reinforcement size has been found to improve yield strength in other aluminum matrix composites [27], which supports the results found here.

Table 3

The estimated yield strengths of the unreinforced aluminum alloy and reinforced composites and the contributions from the various strengthening mechanisms.

\begin{tabular}{ccccc}
\hline & $\begin{array}{c}\text { Estimated Yield } \\
\text { Strength (MPa) }\end{array}$ & $\begin{array}{c}\text { Contribution } \Delta \sigma_{\text {dis }} \\
(\mathrm{MPa})\end{array}$ & $\begin{array}{c}\text { Contribution } \Delta \sigma_{H P} \\
(\mathrm{MPa})\end{array}$ & $\begin{array}{c}\text { Contribution } \\
\Delta \sigma_{l}(\mathrm{MPa})\end{array}$ \\
\hline $\mathrm{Al}-\mathrm{B}_{4} \mathrm{C}-1$ & 942 & 241 & 684 & 17 \\
$\mathrm{Al}-\mathrm{B}_{4} \mathrm{C}-2$ & 862 & 135 & 710 & 17 \\
$\mathrm{NR}-\mathrm{Al}$ & 728 & 133 & 595 & - \\
\hline
\end{tabular}

Notes:

$\Delta \sigma_{\text {dis }}$ : Dislocation strengthening resulting from Orowan mechanisms and geometrically necessary dislocations (GNDs) due to modulus mismatch

$\Delta \sigma_{H P}$ : Hall-Petch strengthening due to grain refinement

$\Delta \sigma_{l}:$ Load transfer to reinforcement particles in the composites

\subsection{Rate dependence and its significance}

The influence of strain rate on the three materials was investigated using a series of strain rate jump tests performed on a nanoindenter. Strain rate sensitivity $(m)$ is an indicator of a material's yield or flow strength as a function of strain rate. The strain rate sensitivity was calculated as [6]:

$$
m=\frac{d \ln H}{d \ln \dot{\varepsilon}},
$$

where $H$ is the hardness and $\dot{\varepsilon}$ is the indentation strain rate defined by $\dot{\varepsilon}=\dot{P} / \mathrm{P}$, with $\dot{P}$ being the loading rate during indentation and $P$ being the load. The results are shown in Fig. 9 and include a high strain rate data point from the dynamic compression tests. It should be noted that unlike conventional coarse grain metals where including high strain rate data usually brings up the SRS value, in the case of Al-5083 and the two Al-MMCs in this work, including the high strain rate data points brings down the SRS values for all 
the materials. As a matter of fact, the nanoindentation-based SRS values for the three materials are $0.053,0.047$ and 0.034 for A1-5083, $\mathrm{Al}-\mathrm{B}_{4} \mathrm{C}-1$ and $\mathrm{Al}-\mathrm{B}_{4} \mathrm{C}-2$, respectively. The SRS of coarse grain Al is typical of metals with face-centered cubic (fcc) structure such as $\mathrm{Cu}$ and $\mathrm{Ni}$, on the order of 0.004 . Refining grain size of fcc metals into ultrafine grain and nanocrystalline regimes has been shown to increase the SRS [52]. It is observed from the indentation rate jump experiments that the three Al-based materials of this work follow the same trend. In other words, the SRS at quasi-static rate, particularly probed by nanoindentation, is controlled by the Al-matrix phase. However, from bulk testing such as uniaxial compression at different strain rates, the results of which are not included here, exhibit a different trend in terms of rate dependence. This observation is similar to those of bulk metallic glasses (BMGs) and other brittle materials where dynamic loading leads to reduced strength, primarily because of sensitivity to stress concentration [53].

From the Hart criterion [54] for a strain rate sensitive material

$$
\frac{1}{\sigma}\left(\frac{\partial \sigma}{\partial \varepsilon}\right)_{\dot{\varepsilon}}-1+m \leq 0
$$

a greater SRS $(m)$ value makes the material less susceptible to inhomogeneous deformation even in the absence of strain hardening. While Hart and others [55] were interested in the stability during tensile deformation, this stabilizing factor also plays a role in the likelihood of adiabatic shear band formation during compression [56]. Looking at the SRS values in Table 2 and Fig. 9 it can be seen that bulk strain rate sensitivity of the materials is quite low, similar to that of coarse grain FCC metals such as copper $[57,58]$.

The $m$ value for these UFG aluminum materials is unusually small if the high rate data point is included, as $m$ tends to increase with grain refinement for FCC metals. Carreker and Hibbard [58] were one of the first to discover the grain size dependence of the strain rate sensitivity, with values ranging from $\sim 0.004$ for coarse grain copper to $\sim 0.0072$ for slightly more refined grains. Further investigations such as those by E. Ma [59] on UFG copper, and J. May [60] on UFG aluminum found that relatively large $m$ values of 0.03 and 0.014 , respectively, could be obtained. As such, the low strain rate 
sensitivity of the three UFG materials in this investigation is uncommon, though similar values have been reported previously [61]. The low $m$ values found here contribute to the deformation behavior that is discussed in the following section.

\subsection{Plastic deformation and shear band formation}

Looking at the behavior of the three materials after yielding, there is a clear difference between the composite and alloy behavior, as well as the quasi-static and dynamic behavior. The unreinforced alloy strain hardens under both quasi-static and dynamic strain rates, while $\mathrm{Al}-\mathrm{B}_{4} \mathrm{C}-1$ is elastic-nearly perfectly plastic in the quasi-static regime and both $\mathrm{Al}-\mathrm{B}_{4} \mathrm{C}-1$ and $\mathrm{Al}-\mathrm{B}_{4} \mathrm{C}-2$ strain soften during dynamic loading. In regards to the microstructure, the composites and alloy are very similar, as both are stabilized by Zener pinning that results from dispersoids that formed during cryomilling [2, 31, 62]. The difference between the composite and alloy behavior is therefore due to the addition of boron carbide.

As strain softening is often a result of microstructural damage, the difference in the plastic response of $\mathrm{Al}-\mathrm{B}_{4} \mathrm{C}-1$ between quasi-static and dynamic loading is microcracking that occurs at the reinforcement-matrix interface. While this process would occur at both quasi-static and dynamic strain rates in the composites, at dynamic rates the addition of thermal effects from adiabatic heating results in overall strain softening. As seen in Fig. 6 (a), when thermal softening is not a factor due to low strain rates, any microstructural damage leads to an almost steady state, perfectly plastic deformation.

When considering adiabatic shear band (ASB) formation, low strain rate sensitivity, low strain hardening and high thermal softening are all known to make materials more susceptible to the development of ASBs [56]. Due to the strain hardening that occurs in the unreinforced alloy as well as the lack of microstructural damage, no ASBs are seen at either quasi-static or dynamic strain rates. Conversely, the composite samples exhibited ASB formation during dynamic loading due to the transient strain hardening and significant strain softening that occurs. However the strain hardening, though limited, which occurs in the composites at quasi-static strain rates, along with the additional time for thermal diffusion are sufficient to prevent the formation of ASBs. 
The formation of two conjugate ASBs exhibited by $\mathrm{Al}-\mathrm{B}_{4} \mathrm{C}-1$ and $\mathrm{Al}-\mathrm{B}_{4} \mathrm{C}-2$ is in contrast to aluminum MMCs that consist of larger, micron-sized reinforcements [17] where shear banding occurs, but is distributed throughout the specimen. It has been shown previously that the introduction of reinforcing particles can inhibit ASB development [63], though based on the observation of these nanometric reinforced MMCs, it appears that by reducing the particle size to the nanoscale, ASB formation is no longer suppressed.

The mechanical behavior of $\mathrm{Al}-\mathrm{B}_{4} \mathrm{C}-1$ under quasi-static loading is quite interesting as it exhibited a strain to failure of over $15 \%$, only slightly less than that exhibited during dynamic loading. In comparison, a similar aluminum alloy reinforced with micron-sized boron carbide and coarse-grained matrix material to aid in deformation, was tested at the same quasi-static strain rate and sustained less than 5\% strain [17] before failure. Previous investigations have found impressive strain to failure of up to $\sim 25 \%$ in other aluminum based nanocomposites [24], however the composites Al- $\mathrm{B}_{4} \mathrm{C}-1$ and $\mathrm{Al}-\mathrm{B}_{4} \mathrm{C}-2$ do not contain any coarse-grained matrix material and did not require the further step of undergoing extrusion. The significant variation in strain-tofailure at quasi-static strain rates indicates the importance of reinforcement size on the deformation of these types of composite material.

A common phenomenon in ceramic reinforced composites is microcracking, where small cracks form at the interface of the metal matrix and reinforcing material, and it has previously been suggested [25] that this process is the source of the improved strain-to-failure at dynamic strain rates. While no microcracks at the interface between the matrix and $\mathrm{B}_{4} \mathrm{C}$ were observed in this investigation, enhanced plasticity at dynamic strain rates was observed and it is an area that will receive further analysis.

In the interest of predicting the likelihood of adiabatic shear band formation, an analysis in the form of that taken by Grady [64] was performed. In this treatment the shear band is considered as a two-material system; the shear-band process zone which exists at the front of the shear band and propagates along the shear plane, and the thermally-softened material behind the process zone where the flow stress relaxes to zero and well-lubricated shear slip occurs. This analysis is actually an analogy to mode II fracture, in which the shear band nucleates and progresses with a finite growth rate and does not form along the full shear plane simultaneously [65]. Such behavior is supported 
by post-loading surface analysis of the composite samples as shown in Fig. 7 (b) and 7 (c). Shear localization is more concentrated at one end of the shear band, and the amount of deformation decreases progressing along the band.

In order to make the model more accessible and quickly applied, a twodimensional approach is simplified to a one-dimensional analysis, but the time variation of temperature and stress is retained. A specific model of thermoplastic shear deformation is used to calculate the dissipation within the shear-band process zone, and while the key equations are presented, a thorough analysis can be found in the literature $[64,66]$. In this model, it is assumed that the stress and dissipation rate only differ from zero in the process zone, and that the shear band has a defined thickness within which temperature and shear strain are constant. Linear thermal softening is assumed, and takes the form,

$$
\tau=\tau_{y}(1-\alpha \theta)
$$

where $\alpha$ is a softening coefficient, $\tau_{y}$ is the shear flow stress, taken as $57 \%$ of the compressive yield stress following a von Mises yield criterion, and $\theta$ is the temperature excursion above ambient temperature. Solutions where the flow stress relaxes to zero due to thermal softening are sought, when the material has surpassed a critical shear displacement, $\psi_{c}$. An implicit expression for the critical shear displacement can be formed,

$$
\psi_{c}=\sqrt{\frac{32 \tau_{y} \dot{\gamma}}{9 \rho \chi_{a}^{3}}\left(\frac{\alpha \tau_{y}}{2 c_{a}} \Psi_{c}-1\right)^{3}} .
$$

The global shear strain rate is represented by $\dot{\gamma}$ and the properties $\chi_{a}=2 \chi / a^{2}$ and $c_{a}=\rho c a / 2$ are the areal heat transfer and areal heat capacity, where $C$ and $\chi$ are the bulk specific heat and thermal diffusivity coefficients. The critical displacement can be 
related to the plastic dissipation within the shear band through the relation $\Gamma_{c}=\tau_{y} \psi_{c} / 2$, and for an optimum shear band thickness $a_{0}$, the shear band dissipation energy is,

$$
\Gamma_{c 0}=\frac{\rho c}{\alpha}\left(\frac{9 \rho^{3} c^{2} \chi^{3}}{\tau_{y}^{3} \alpha^{2} \dot{\gamma}}\right)^{1 / 4} .
$$

The shear band dissipation energy calculated in Eq. (11) based on one-dimensional analysis, provides the shear band dissipation energy expended within the process zone $\Gamma_{c 0}=\Gamma_{s}$. A shear band toughness, approximating the susceptibility of a material to ASB formation, can then be introduced with the relation $K_{s}=\sqrt{2 G_{m} \Gamma_{s}}$. The material parameters and the resultant toughness values obtained are provided in Table 4. Based on Eq. 11, it can be seen that increases in density, specific heat capacity, and thermal diffusivity are stabilizing factors, while increases in flow stress result in a greater susceptibility to ASB formation.

In order to determine the influence the $\mathrm{B}_{4} \mathrm{C}$ reinforcement had on the material parameters of the composites, the rule of mixtures was used. Boron carbide has a slightly higher specific heat capacity than Al 5083 at room temperature, and a somewhat lower density, yielding little change to the calculated toughness. Even the low thermal conductivity of $17(\mathrm{~W} / \mathrm{K} \cdot \mathrm{m})$ compared to Al 5083's $117(\mathrm{~W} / \mathrm{K} \cdot \mathrm{m})$ has a small effect once the volume fraction of boron carbide is taken into account. A thermal softening factor of $\alpha=8 \times 10^{-4}$ was chosen for the three materials based on those used by Grady [64] and the increased microstructural stability imparted by secondary nanoscale particles. As a result, the largest factor contributing to the shear band toughness is the yield stress of the material, which was highest in the composite materials. While the resultant shear band toughness values are not significantly different, they do match the trend observed during dynamic loading. 
Table 4

Material parameters and resultant shear band dissipation energy and shear band toughness values for cryomilled $\mathrm{Al} 5083$ and the composites $\mathrm{Al}-\mathrm{B}_{4} \mathrm{C}-1$ and $\mathrm{Al}-\mathrm{B}_{4} \mathrm{C}-2$.

\begin{tabular}{|c|c|c|c|c|c|c|c|c|}
\hline Material & $\begin{array}{l}\rho \\
\left(\mathrm{kg} / \mathrm{m}^{3} \times 10^{3}\right)\end{array}$ & $\begin{array}{l}\alpha \\
\left(K^{-1} \times 10^{-4}\right)\end{array}$ & $\begin{array}{l}\chi \\
\left(m^{2} / s \times 10^{-4}\right)\end{array}$ & $\begin{array}{l}\text { C } \\
(\mathrm{J} / \mathrm{kg} \cdot \mathrm{K})\end{array}$ & $\begin{array}{l}\tau_{y} \\
(G P a)\end{array}$ & $\begin{array}{l}G_{m} \\
(G P a)\end{array}$ & $\begin{array}{l}\Gamma_{s} \\
\left(k J / m^{2}\right)\end{array}$ & $\begin{array}{l}K_{s} \\
\left(M N m^{-3 / 2}\right)\end{array}$ \\
\hline Al 5083 & 2660 & 8.0 & 0.489 & 900 & 0.335 & 27 & 14.4 & 27.9 \\
\hline $\mathrm{Al}-\mathrm{B}_{4} \mathrm{C}-1$ & 2653 & 8.0 & 0.461 & 903.6 & 0.519 & 27 & 9.94 & 23.2 \\
\hline $\mathrm{Al}-\mathrm{B}_{4} \mathrm{C}-2$ & 2653 & 8.0 & 0.461 & 903.6 & 0.508 & 27 & 10.1 & 23.4 \\
\hline
\end{tabular}

\section{Summary and Concluding Remarks}

The effects of boron carbide reinforcement on the microstructure, plastic deformation and mechanical properties of a high strength aluminum alloy have been investigated. The addition of $\mathrm{B}_{4} \mathrm{C}$ regardless of size $(40 \mathrm{~nm}$ or $500 \mathrm{~nm})$, has been found to improve the yield strength of the metal matrix composites by $30 \%$ while also providing stiffness improvement as compared to the unreinforced alloy. Results also suggest that the further reduction of the reinforcement dimension from $500 \mathrm{~nm}$ to $40 \mathrm{~nm}$ produces a composite with a higher yield strength. Models have been proposed to estimate the yield strength based on material microstructural features and have been found to approximately agree with the experimental results. Additionally, the improved strength and moderate plasticity of the Al composites are exhibited at both quasi-static $\left(\begin{array}{lll}1 & 10^{-3} \mathrm{~s}^{-1}\end{array}\right)$ and dynamic $\left(4 \times 10^{3} \mathrm{~s}^{-1}\right)$ strain rates. This improved strain to failure at quasi-static strain rates is a considerable improvement over aluminum alloys reinforced with micron-sized $\mathrm{B}_{4} \mathrm{C}$, though it does come at the cost of reduced yield strength.

In addition, the introduction of nanoscale boron carbide results in the development of adiabatic shear banding under uniaxial high strain rate compression. This behavior is not observed in the unreinforced alloy as its greater ability to strain harden and the increased time for thermal diffusion removes this deformation pathway. The occurrence of adiabatic shear banding under dynamic loading can be rationalized from a mechanistic model that analogized the initiation and propagation of ASB to those of a model II crack. A simple estimation indicates that the un-reinforced aluminum alloy exhibits the highest ASB toughness. The ASB toughness of the reinforced materials is reduced, making these materials more prone to ASB. 
Exhibiting excellent plasticity at dynamic and quasi-static strain rates considering the UFG nature of the composites, and demonstrating increased strength, these nanoreinforced MMCs are of great interest for continued study.

\section{Acknowledgements:}

N. Behm, J. Shen and Q. Wei acknowledge the support from US Army Research Laboratory under Contract Nos. W911QX-08-0073 and W911NF-14-2-0061. H. Yang, K. Ma, E.J. Lavernia, and J.M. Schoenung acknowledge financial support from the Office of Naval Research under the guidance of Rod Peterson and Bill Golumbfskie (ONR N00014-12-C-0241).

\section{References}

[1] Clausen AH, Borvik T, Hopperstad OS, Benallal A. Flow and fracture characteristics of aluminium alloy AA5083-H116 as function of strain rate, temperature and triaxiality. Mater Sci Eng A-Struct Mater Prop Microstruct Process. 2004;364:260-72.

[2] Han BQ, Lee Z, Nutt SR, Lavernia EJ, Mohamed FA. Mechanical properties of an ultrafine-grained Al-7.5 pct Mg alloy. Metallurgical and Materials Transactions aPhysical Metallurgy and Materials Science. 2003;34:603-13.

[3] Yang DK, Hodgson PD. Tough ultrafine-grained Ti through multilayering and grading. Scripta Materialia.68:309-12.

[4] Valiev R. Nanostructuring of metals by severe plastic deformation for advanced properties. Nature Materials. 2004;3:511-6.

[5] Valiev RZ. Structure and mechanical properties of ultrafine-grained metals. Mater Sci

Eng A-Struct Mater Prop Microstruct Process. 1997;234:59-66.

[6] Wei Q, Cheng S, Ramesh KT, Ma E. Effect of nanocrystalline and ultrafine grain sizes on the strain rate sensitivity and activation volume: fcc versus bcc metals. Mater Sci Eng A-Struct Mater Prop Microstruct Process. 2004;381:71-9.

[7] Ogawa F, Masuda C. Microstructure evolution during fabrication and microstructureproperty relationships in vapour-grown carbon nanofibre-reinforced aluminium matrix composites fabricated via powder metallurgy. Composites Part a-Applied Science and Manufacturing. 2015;71:84-94.

[8] Rajan TPD, Pillai RM, Pai BC. Reinforcement coatings and interfaces in aluminium metal matrix composites. Journal of Materials Science. 1998;33:3491-503.

[9] Nukami T, Flemings MC. IN-SITU SYNTHESIS OF TIC PARTICULATEREINFORCED ALUMINUM-MATRIX COMPOSITES. Metallurgical and Materials Transactions a-Physical Metallurgy and Materials Science. 1995;26:1877-84. [10] Aghajanian MK, Rocazella MA, Burke JT, Keck SD. THE FABRICATION OF METAL MATRIX COMPOSITES BY A PRESSURELESS INFILTRATION TECHNIQUE. Journal of Materials Science. 1991;26:447-54. [11] Iseki T, Kameda T, Maruyama T. INTERFACIAL REACTIONS BETWEEN SIC AND ALUMINUM DURING JOINING. Journal of Materials Science. 1984;19:1692-8. 
[12] Jiang L, Ma K, Yang H, Li M, Lavernia EJ, Schoenung JM. The Microstructural Design of Trimodal Aluminum Composites. Jom. 2014;66:898-908.

[13] Vogt RG, Zhang Z, Topping TD, Lavernia EJ, Schoenung JM. Cryomilled

aluminum alloy and boron carbide nano-composite plate. Journal of Materials Processing Technology. 2009;209:5046-53.

[14] Ye JC, He JH, Schoenung JM. Cryomilling for the fabrication of a particulate B4C reinforced Al nanocomposite: Part I. Effects of process conditions on structure.

Metallurgical and Materials Transactions a-Physical Metallurgy and Materials Science. 2006;37A:3099-109.

[15] Ye J, Han BQ, Lee Z, Ahn B, Nutt SR, Schoenung JM. A tri-modal aluminum based composite with super-high strength. Scripta Materialia. 2005;53:481-6.

[16] Zhang H, Ye J, Joshi SP, Schoenung JM, Chin ESC, Ramesh KT. Rate-dependent behavior of hierarchical Al matrix composites. Scripta Materialia. 2008;59:1139-42.

[17] Vogt R, Zhang Z, Huskins E, Ahn B, Nutt S, Ramesh KT, et al. High strain rate deformation and resultant damage mechanisms in ultrafine-grained aluminum matrix composites. Mater Sci Eng A-Struct Mater Prop Microstruct Process. 2010;527:5990-6. [18] Zhang HT, Ye JC, Joshi SP, Schoenung JM, Chin ESC, Gazonas GA, et al. Superlightweight nanoengineered aluminum for strength under impact. Advanced Engineering Materials. 2007;9:355-9.

[19] Zhou ZS, Wu GH, Jiang LT, Li RF, Xu ZG. Analysis of morphology and microstructure of B4C/2024Al composites after $7.62 \mathrm{~mm}$ ballistic impact. Materials \& Design. 2014;63:658-63.

[20] Ramnath BV, Elanchezhian C, Jaivignesh M, Rajesh S, Parswajinan C, Ghias ASA. Evaluation of mechanical properties of aluminium alloy-alumina-boron carbide metal matrix composites. Materials \& Design. 2014;58:332-8.

[21] Cao BY, Joshi SP, Ramesh KT. Strengthening mechanisms in cryomilled ultrafinegrained aluminum alloy at quasi-static and dynamic rates of loading. Scripta Materialia. 2009;60:619-22.

[22] Domnich V, Reynaud S, Haber RA, Chhowalla M. Boron Carbide: Structure, Properties, and Stability under Stress. Journal of the American Ceramic Society. 2011;94:3605-28.

[23] Sairam K, Sonber JK, Murthy T, Subramanian C, Hubli RC, Suri AK. Development of B4C-HfB2 composites by reaction hot pressing. International Journal of Refractory Metals \& Hard Materials. 2012;35:32-40.

[24] Zhang ZH, Topping T, Li Y, Vogt R, Zhou YZ, Haines C, et al. Mechanical behavior of ultrafine-grained Al composites reinforced with B4C nanoparticles. Scripta Materialia. 2011;65:652-5.

[25] Jiang L, Wen H, Yang H, Hu T, Topping T, Zhang D, et al. Influence of lengthscales on spatial distribution and interfacial characteristics of $\mathrm{B} 4 \mathrm{C}$ in a nanostructured $\mathrm{Al}$ matrix. Acta Materialia. 2015;89:327-43.

[26] Yang H, Topping TD, Wehage K, Jiang L, Lavernia EJ, Schoenung JM. Tensile behavior and strengthening mechanisms in a submicron B4C-reinforced Al trimodal composite. Mater Sci Eng A-Struct Mater Prop Microstruct Process. 2014;616:35-43. [27] Chawla N, Andres C, Jones JW, Allison JE. Effect of SiC volume fraction and particle size on the fatigue resistance of a $2080 \mathrm{Al} / \mathrm{SiCp}$ composite. Metallurgical and Materials Transactions a-Physical Metallurgy and Materials Science. 1998;29:2843-54. 
[28] Alpas AT, Zhang J. EFFECT OF MICROSTRUCTURE (PARTICULATE SIZE AND VOLUME FRACTION) AND COUNTERFACE MATERIAL ON THE SLIDING WEAR-RESISTANCE OF PARTICULATE-REINFORCED ALUMINUM-MATRIX COMPOSITES. Metallurgical and Materials Transactions a-Physical Metallurgy and Materials Science. 1994;25:969-83.

[29] Singh PM, Lewandowski JJ. EFFECTS OF HEAT-TREATMENT AND REINFORCEMENT SIZE ON REINFORCEMENT FRACTURE DURING TENSION TESTING OF A SIC(P) DISCONTINUOUSLY REINFORCED ALUMINUM-ALLOY. Metallurgical Transactions a-Physical Metallurgy and Materials Science. 1993;24:253143.

[30] Witkin DB, Lavernia EJ. Synthesis and mechanical behavior of nanostructured materials via cryomilling. Prog Mater Sci. 2006;51:1-60.

[31] Tellkamp VL, Melmed A, Lavernia EJ. Mechanical behavior and microstructure of a thermally stable bulk nanostructured Al alloy. Metallurgical and Materials Transactions a-Physical Metallurgy and Materials Science. 2001;32:2335-43.

[32] Follansbee P. ASM Handbook. Materials Park, OH: ASM International; 1985.

[33] Guo YZ, Behm NA, Ligda JP, Li YL, Pan Z, Horita Z, et al. Critical issues related to instrumented indentation on non-uniform materials: Application to niobium subjected to high pressure torsion. Mater Sci Eng A-Struct Mater Prop Microstruct Process.

2013;586:149-59.

[34] Li Y, Liu W, Ortalan V, Li WF, Zhang Z, Vogt R, et al. HRTEM and EELS study of aluminum nitride in nanostructured Al 5083/B4C processed via cryomilling. Acta Mater. 2010;58:1732-40.

[35] Goswami R, Spanos G, Pao PS, Holtz RL. Precipitation behavior of the beta phase in Al-5083. Mater Sci Eng A-Struct Mater Prop Microstruct Process. 2010;527:1089-95. [36] Zener C, Hollomon JH. Effect of strain rate upon plastic flow of steel. Journal of Applied Physics. 1944;15:22-32.

[37] Gleiter H. NANOCRYSTALLINE MATERIALS. Prog Mater Sci. 1989;33:223315.

[38] Clyne TW, Withers PJ. An Introduction to Metal Matrix Composites. Cambridge: University Press; 1993.

[39] Hall EO. The deformation and ageing of mild steel: III. Discussion of results.

Proceedings of the Physical Society B, London. 1951;64:747-53.

[40] Petch NJ. The cleavage strength of polycrystals. Journal of Iron and Steel Institute. 1953;174:25-8.

[41] Last HR, Garrett RK. Mechanical behavior and properties of mechanically alloyed aluminum alloys. Metallurgical and Materials Transactions a-Physical Metallurgy and Materials Science. 1996;27:737-45.

[42] Davis J. ASM Specialty Handbook: Aluminum and Aluminum Alloys. Materials

Park, OH: ASM International; 1994.

[43] Lloyd DJ. PARTICLE-REINFORCED ALUMINUM AND MAGNESIUM MATRIX COMPOSITES. Int Mater Rev. 1994;39:1-23.

[44] Argon AS. Physics of Strength and Plasticity. MIT: MIT Press; 1969.

[45] Brown LM, Ham RK. Strengthening Methods in Crystals. In: Kelly A, Nicholson RB, editors. Strengthening Methods in Crystals. Amsterdam: Elsevier; 1971. p. 9-70. 
[46] Ramakrishnan N. An analytical study on strengthening of particulate reinforced metal matrix composites. Acta Mater. 1996;44:69-77.

[47] Nardone VC, Prewo KM. ON THE STRENGTH OF DISCONTINUOUS SILICONCARBIDE REINFORCED ALUMINUM COMPOSITES. Scripta Metallurgica.

1986;20:43-8.

[48] Vogt R, Zhang Z, Li Y, Bonds M, Browning ND, Lavernia EJ, et al. The absence of thermal expansion mismatch strengthening in nanostructured metal-matrix composites.

Scripta Materialia. 2009;61:1052-5.

[49] Taya M, Lulay KE, Lloyd DJ. STRENGTHENING OF A PARTICULATE METAL MATRIX COMPOSITE BY QUENCHING. Acta Metall Mater. 1991;39:73-87.

[50] Tang F, Anderson IE, Gnaupel-Herold T, Prask H. Pure Al matrix composites produced by vacuum hot pressing: tensile properties and strengthening mechanisms. Mater Sci Eng A-Struct Mater Prop Microstruct Process. 2004;383:362-73.

[51] Nan CW, Clarke DR. The influence of particle size and particle fracture on the elastic/plastic deformation of metal matrix composites. Acta Mater. 1996;44:3801-11.

[52] Wei Q. Strain rate effects in the ultrafine grain and nanocrystalline regimes--its influence on some constitutive behavior. Journal of materials science. 2007;42:1709-27. [53] Hufnagel TC, Jiao T, Li Y, Xing LQ, Ramesh KT. Deformation and failure of Zr57Ti5CU20Ni8A110 bulk metallic glass under quasi-static and dynamic compression. Journal of Materials research. 2002;17:1441-5.

[54] Hart EW. THEORY OF TENSILE TEST. Acta Metallurgica. 1967;15:351-\&. [55] Wang YM, Ma E. Three strategies to achieve uniform tensile deformation in a nanostructured metal. Acta Mater. 2004;52:1699-709.

[56] Dodd B, Bai Y. Adiabatic Shear Localization: Frontiers and Advances. 2nd ed. 22 Jamestown Road, London: Elsevier; 2012.

[57] Follansbee PS, Regazzoni G, Kocks UF. THE TRANSITION TO DRAGCONTROLLED DEFORMATION IN COPPER AT HIGH-STRAIN RATES. Institute of Physics Conference Series. 1984:71-80.

[58] Carreker RP, Hibbard WR. TENSILE DEFORMATION OF HIGH-PURITY COPPER AS A FUNCTION OF TEMPERATURE, STRAIN RATE, AND GRAIN SIZE. Acta Metallurgica. 1953;1:656-\&.

[59] Wang YM, Chen MW, Zhou FH, Ma E. High tensile ductility in a nanostructured metal. Nature. 2002;419:912-5.

[60] May J, Hoppel HW, Goken M. Strain rate sensitivity of ultrafine-grained aluminium processed by severe plastic deformation. Scripta Materialia. 2005;53:189-94.

[61] Korchef A, Njah N, Masmoudi J, Kolsi A, Champion Y, Guerin S, et al. Evolution of the mechanical properties of aluminum containing Al8Fe2Si precipitates during equal channel angular pressing. Advanced Engineering Materials. 2004;6:639-43.

[62] Perez RJ, Huang B, Lavernia EJ. Thermal stability of nanocrystalline Fe-10 wt.\% Al produced by cryogenic mechanical alloying. Nanostructured Materials. 1996;7:565-72. [63] Lee SH, Cho KM, Kim KC, Choi WB. ADIABATIC SHEAR BAND FORMATION IN AL-SIC(W) COMPOSITES. Metallurgical Transactions a-Physical Metallurgy and Materials Science. 1993;24:895-900.

[64] Grady DE. DISSIPATION IN ADIABATIC SHEAR BANDS. Mechanics of Materials. 1994;17:289-93. 
[65] Shockey DA, Curran DR, Seaman L. Development of Improved Dynamic Failure Models. SRI International Technical Report. 1985.

[66] Grady DE. PROPERTIES OF AN ADIABATIC SHEAR-BAND PROCESS ZONE. Journal of the Mechanics and Physics of Solids. 1992;40:1197-215. 